\title{
UTILIZAÇÃO DO MÉTODO FMEA NA IDENTIFICAÇÃO E ANÁLISE DOS IMPACTOS AMBIENTAIS CAUSADOS PELOS POSTOS DE COMBUSTÍVEIS: UM ESTUDO DE CASO
}

\author{
USE OF THE FMEA METHOD IN \\ THE IDENTIFICATION AND ANALYSIS OF \\ ENVIRONMENTAL IMPACTS CAUSED \\ BY FUEL STATIONS: A CASE STUDY
}

\author{
Recebido: 07-08-2012 \\ Aceito: 16-10-2013 \\ Dayanna dos Santos Costa Maciel ${ }^{1}$ \\ Lúcia Santana de Freitas ${ }^{2}$
}

\section{RESUMO}

O varejo de combustíveis é uma das atividades que gera impactos significativos ao meio ambiente. Nesse sentido, o presente estudo tem como objetivo identificar e analisar os potenciais impactos ambientais causados pelas atividades desenvolvidas por um posto de distribuição de combustíveis. Para isso, utilizou-se como base teórica o modelo de Análise de Falha e seus Efeitos (FMEA), proposto por Vandenbrande (1998). Quanto à metodologia, a pesquisa classifica-se como exploratória e descritiva, utilizando-se do método de estudo de caso. Para atingir aos objetivos propostos, foram coletados dados primários (obtidos por meio de entrevistas semiestruturadas com o proprietário, o gerente, os frentistas, as vendedoras e as cozinheiras do restaurante, além da observação in loco) e secundários (obtidos por meio de relatórios, artigos, licenças ambientais, dentre outros documentos). Os resultados indicam um alto risco de contaminação humana; um médio risco de incêndio e de contaminação de água e solo; e um baixo risco no que tange à geração de resíduos. A conclusão é de que a utilização do método FMEA contribui para uma constante avaliação do risco ambiental e para a adoção de ações de mitigação, o que permitirá à organização melhor seus processos e acompanhar tais melhorias por meio da mensuração dos índices de criticidade.

Palavras-chave: FMEA; postos de distribuição de combustíveis; impacto ambiental.

1 Possui graduação em Administração pela Universidade Federal de Campina Grande - UFCG. Atualmente é mestranda de Recursos Naturias da Universidade Federal de Campina Grande - UFCG. Campina Grande, Paraíba, Brasil. E-mail: dayanna-costa@ hotmail.com

2 Possui graduação em Administração pela Universidade Federal da Paraíba - UFPB. Doutorado em Administração pela Universidade de Valladolid. Atualmente é professora na Universidade Federal de Campina Grande - UFCG. Campina Grande, Paraíba, Brasil.E-mail: luciasf@ch.ufcg.edu.br 


\begin{abstract}
The retail of fuel is one of the activities that generates significant impacts on the environment. In this sense, this study aims to identify and analyze the potential environmental impacts caused by the activities carried out by a fuel station in the light of the method Failure Analysis and its Effects (FMEA). It was used as a theoretical basis the model proposed by Vandenbrande FMEA (1998). Regarding the methodology, the research is classified as exploratory and descriptive, using the case study method. To this end, we collected primary and secondary data, the primary were obtained through semi-structured interviews with the owner, manager, attendants, vendors and cookers of the restaurant, and on-site observation. As for the secondary data were obtained through reports, articles, environmental permits, among others. As a result of impact was identified as the high risk of human exposure, medium risk of contamination of soil and water and fire, and the low risk of waste, it is concluded therefore that the use of the FMEA method contributes for the constant evaluation of environmental risk and the adoption of mitigation actions, which will lead the organization to improve its processes and monitoring of such improvements by measuring the levels of criticality.
\end{abstract}

Keywords: FMEA, fuel stations; environmental impact.

\title{
1 INTRODUÇÃO
}

As questões acerca do meio ambiente cada vez mais ganham proporção mundial e são alvos de discussões acadêmicas, governamentais e empresariais. Isso se deve, em especial, às manifestações de problemas ambientais globais, tais como aumento de temperatura da terra, destruição da camada de ozônio, esgotamento acelerado dos recursos naturais; dentre outros. Como consequência, tais problemas estimulam a busca de um novo modelo de crescimento econômico que considere a preservação do meio ambiente e a solução dos problemas ambientais por meio de iniciativas individuais, empresariais e públicas.

No que tange às iniciativas empresariais, estas devem reduzir ao máximo seu impacto ambiental negativo. Dessa forma, as empresas tendem a adaptarem-se às pressões dos consumidores (iniciativas individuais) e às imposições normativas (iniciativas públicas) que as obrigam a conceber produtos e sistemas de produção e distribuição que minimizem os impactos ambientais ao longo das atividades desempenhadas, segundo Velter et al. (2009). No Brasil, alguns estudos acadêmicos já se dedicaram à questão ambiental, ora buscando entender como as empresas estão agindo em relação ao meio ambiente, ora buscando verificar a visão e a sensibilidade dos consumidores sobre essa questão. Desse modo, a variável ambiental passou a fazer parte dos processos decisórios das organizações, e sua gestão é imprescindível para a manutenção dos negócios (PORTUGAL JR; PORTUGAL, 2010).

Nesse contexto, faz-se necessário conceituar a gestão ambiental empresarial, que, segundo Donaire (2007), refere-se a um conjunto de políticas, programas e práticas administrativas e operacionais que levam em conta a saúde e segurança das pessoas; a proteção do meio ambiente por meio da eliminação/minimização de impactos e danos ambientais; e a implantação, operação, ampliação, realocação e desativação de atividades, em todas as fases do ciclo de vida de um produto. $O$ objetivo maior da gestão ambiental deve ser a busca permanente da melhoria da qualidade ambiental dos serviços, dos produtos e do ambiente de trabalho, independentemente do tipo da organização (pública ou privada). Para tanto, essas organizações devem ter consciência dos impactos ambientais causados por suas atividades de produção, distribuição ou comercialização.

Considera-se impacto ambiental qualquer alteração no meio ou em algum de seus componentes por determinada ação ou atividade. Essas alterações causadas no contexto empresarial precisam ser identificadas e avaliadas, pois apresentam variações relativas, podendo ser positivas ou negativas, grandes ou pequenas. O objetivo de estudar os impactos ambientais é, principal- 
mente, avaliar as consequências das ações e atividades realizadas pelas organizações, para que seja possível preservar a qualidade do ambiente.

Na literatura relacionada ao impacto ambiental e às organizações, encontram-se vários estudos realizados nos mais variados setores, como metalúrgica, petroquímica, fabricação de embalagens e alumínio e montadora de veículos (SPERANDIO; GASPAR, 2008). Como ferramenta para identificação e diagnóstico de problemas ambientais, Vandenbrande (1998) apresenta um modelo chamado Análise de Falha e seus Efeitos (FMEA), que pode ser aplicado nas mais diversas atividades econômicas que se destacam por ocasionar relevantes impactos ambientais.

No que tange aos postos de combustíveis, por exemplo, estes apresentam como atividade empresarial o comércio varejista de combustíveis fósseis e/ou bicombustíveis, podendo desempenhar diversas atividades, além do recebimento, armazenamento e fornecimento dos combustíveis. Exemplos disso são a realização da troca de óleo e de procedimentos de escritório, bem como a presença de restaurante e loja de conveniência. É fato, portanto, que suas atividades primárias causam impactos ambientais, pois envolvem produtos químicos (gasolina, álcool e óleo diesel), considerados potencialmente poluidores, podendo gerar, de forma abrangente, resíduos que proporcionarão a contaminação humana, do solo e da água, além de risco de incêndio. É válido frisar que essa atividade sofre grande influência e regulamentação ambiental de órgãos responsáveis pelo setor de petróleo e gás, como a Agência Nacional do Petróleo (ANAP), e de órgãos de controle ambiental, a exemplo do Conselho Nacional do Meio Ambiente (CONAMA).

Diante desse contexto, o presente estudo tem como objetivo identificar e analisar os potenciais impactos ambientais causados pelas atividades desenvolvidas em um posto de distribuição de combustíveis, à luz do método FMEA. Este estudo se justifica por propiciar, através da aplicação da ferramenta FMEA, a identificação dos impactos ambientais e apresentação de uma escala de priorização baseada na aplicação de índices de criticidade, permitindo, assim, a avaliação dos maiores riscos ambientais e facilitando a visualização das possíveis ações de melhoria e controle, que poderão servir como rica fonte de informação e orientação às práticas ambientais da empresa em estudo.

Para tanto, além da presente introdução, este artigo apresenta, a seguir: referencial teórico; metodologia, caracterizando o tipo de pesquisa e a coleta de dados; análise dos resultados, destacando a aplicação do FMEA; e, por último, conclusões.

\section{FUNDAMENTAÇÃO TEÓRICA}

\subsection{Impactos ambientais causados pelos postos de distribuição de combustiveis}

Segundo Rocha et al. (2004), de forma integrada, os potencias e reais impactos causados pelas atividades dos postos de distribuição de combustíveis podem ser classificados em quatro tipos: contaminação humana; contaminação do solo e da água subterrânea; incêndio; e resíduos. Essa classificação advém de diferentes áreas de estudo, tais como saúde, geologia, engenharia, dentre outras que tratam tais impactos de forma separada, e propicia uma visão ampla dos impactos ambientais causados pelas atividades realizadas nesses estabelecimentos, bem como dos aspectos legais e das principais ações de controle e prevenção. Cabe ressaltar que é considerado como impacto ambiental toda e qualquer alteração das propriedades físicas, químicas e biológicas do meio ambiente, causada por qualquer forma de matéria ou energia resultante de atividades humanas que, de maneira direta ou indireta, venham a afetar a saúde, a segurança e o bem-estar da população; as atividades sociais e econômicas; a biota; as condições estéticas e sanitárias do meio ambiente; e a qualidade dos recursos naturais (Resolução CONAMA n.o 001, de 23 de janeiro de 1986, Art. 1.). 
Quanto à contaminação humana, esta é causada por hidrocarbonetos, via contato com o combustível ou via aspiração dos gases oriundos destes. Esse tipo de contaminação pode ser dermal, respiratória e oral, destacando-se o fato de que cada tipo de combustível e via de contaminação produzem efeitos específicos. Tendo em vista que os principais combustíveis comercializados são a gasolina, o álcool hidrato e o óleo diesel, o Quadro 1, exposto a seguir, apresenta alguns efeitos da contaminação por esses tipos de combustíveis.

\begin{tabular}{|c|c|c|c|}
\hline \multirow{2}{*}{$\begin{array}{c}\text { Via de } \\
\text { contaminação }\end{array}$} & Gasolina & Álcool Etílico Hidrato & Óleo Diesel \\
\hline & \multicolumn{3}{|c|}{ Efeitos da contaminação } \\
\hline Respiratória & $\begin{array}{l}\text { Tontura, dor de cabeça, } \\
\text { dificuldade respiratória } \\
\text { ou perda da consciência, } \\
\text { irritação das vias aéreas e } \\
\text { náuseas. }\end{array}$ & $\begin{array}{l}\text { Dor de cabeça, sonolência } \\
\text { e lassidão. }\end{array}$ & $\begin{array}{l}\text { Depressores do sistema nervoso, } \\
\text { irritação das vias respiratórias, } \\
\text { náuseas, dor de cabeça, tontura, } \\
\text { vertigem, inconsciência e até coma } \\
\text { e morte em exposição severa. }\end{array}$ \\
\hline Oral & $\begin{array}{l}\text { Irritação da parede do es- } \\
\text { tômago. }\end{array}$ & $\begin{array}{l}\text { Absorvido em altas doses } \\
\text { pode ocasionar alucina- } \\
\text { ções visuais e embriaguez. }\end{array}$ & $\begin{array}{l}\text { Pneumonia química e edema } \\
\text { pulmonar. }\end{array}$ \\
\hline Dermal & Irritação e dermatite. & Irritação & Irritação e conjuntivite. \\
\hline
\end{tabular}

Quadro 1 - Efeitos da contaminação humana.

Fonte: elaborado a partir de Loureiro et al. ( 2002) e Marques et al. (2003).

No que tange aos impactos de contaminação do solo e das águas subterrâneas, estes são provocados por hidrocarbonetos decorrentes, em grande parte, de vazamentos. Os vazamentos de combustíveis podem ocorrer pelos seguintes motivos: derramamentos superficiais constantes e sucessivos junto às bombas e aos bocais, durante a operação de transferência do produto para o tanque ou o abastecimento, devido à infiltração nas rachaduras do piso do posto; vazamentos na própria bomba de abastecimento, no sistema ou no tanque, devido à corrosão; falhas estruturais ou das tubulações subterrâneas conectadas ao tanque; e instalação inadequada.

A contaminação do solo, especificamente, ocorre por derramamentos de combustíveis e, nos casos de maior gravidade, quando existe ocorrência de vazamentos dos tanques de armazenamento subterrâneos. Dependendo do tipo de solo, os combustíveis podem atingir os lençóis freáticos e gerar a contaminação da vizinhança por meio dos poços que são ocasionalmente usados como fonte de abastecimento de água.

Quanto aos impactos de incêndio, segundo Rocha et al. (2004), estes estão relacionados aos efeitos causados pela sua ocorrência, visto que tais efeitos são prejudiciais aos funcionários, aos clientes, aos proprietários e à vizinhança, podendo ocasionar vítimas fatais. Mediante esse contexto, devem-se manter alguns cuidados no manuseio de produtos inflamáveis, visando evitar incêndios e, consequentemente, o risco às pessoas e ao meio ambiente. Os incêndios podem ser causados por eletricidade estática, nas zonas classificadas como atmosfera explosiva, falha no sistema elétrico devido a curto-circuito, vazamento ou derramamento de combustíveis no piso, dentre outros fatores.

Os resíduos gerados pelas atividades desempenhadas nos postos de combustíveis são bastante diversificados. Segundo Lorenzett e Rossato (2010), os principais resíduos gerados nessas atividades são: vapores de combustíveis; flanelas e estopas contaminadas; efluentes líquidos, como águas oleosas; filtros usados; óleo queimado; lodo tóxico das caixas separadoras de água; e óleo e embalagens de lubrificantes. Para Rocha et al. (2004), os postos de distribuição de combustíveis devem seguir as normas ambientais federais e locais no que se refere à destinação dos seus resíduos perigosos, visto que os impactos ambientais que envolvem tais resíduos são pra- 
ticamente os mesmos causados pelos próprios combustíveis: contaminação humana e do solo, risco de incêndio e poluição do meio ambiente.

Em vista à relevância dos impactos ambientais gerados pelas atividades desenvolvidas nos postos de distribuição de combustíveis, faz-se necessária uma análise desses impactos e a inserção de uma gestão ambiental ativa nesse tipo de organização. Para tanto, pode-se utilizar o método da Análise de Falhas e seus Efeitos (FMEA), explicitado a seguir.

\subsection{Análise de Falha e seus Efeitos (FMEA)}

Conforme Kumru e Kumru (2012), o FMEA é uma técnica analítica que combina a tecnologia e experiência de pessoas na identificação de modos de falha previsível de um produto ou processo e de planejamento para a sua eliminação. É amplamente utilizado na indústria de fabricação, em várias fases do ciclo de vida do produto, e seu uso vem se tornando cada vez maior também na indústria de serviços.

Para Barasuol et al. (2006), após ter sua aplicação em estudos realizados na National Aeronautics and Space Administration (NASA), o FMEA disseminou-se na indústria automobilística, a qual, em grande parte, exige de forma contratual que seus fornecedores de autopeças utilizem tal ferramenta. O FMEA faz uma análise de "baixo para cima" (bottom-up), procurando identificar falhas críticas em cada componente, as suas causas e as devidas consequências, aumentando, desse modo, a qualidade e a confiabilidade das peças produzidas. No entanto, a técnica foi projetada inicialmente a fim de estudar falhas em projetos da aeronáutica e atualmente vem possuindo uma relevante aplicação na identificação e no diagnóstico dos problemas e riscos ambientais (VANDENBRANDE, 1998).

Nesse contexto, tal ferramenta tem como principais objetivos a prevenção dos problemas ambientais mais importantes e o impedimento ou a minimização das consequências geradas pelos possíveis problemas. Vandenbrande (1998) explica que o clássico processo de FMEA pode ser facilmente adaptado a um estudo dos riscos potenciais do ambiente, já que, ao usar uma tabela de pontuação de gravidade, o número de prioridade ambiental pode ser calculado da mesma forma que o número de riscos. Contudo, Andrade (2000), tomando como base a metodologia de Vandenbrande (1998), propõe que o FMEA seja aplicado nas organizações para a análise dos aspectos e impactos ambientais causados por suas atividades.

Segundo este autor, o FMEA pode ser utilizado para esses fins no Sistema de Gestão Ambiental (SGA). Para tanto, ele apresenta um método de aplicação composto por 12 etapas: 1Definição da equipe responsável; 2- Definição dos itens do SGA; 3- Preparação prévia para coleta de dados; 4- Pré-filtragem dos aspectos ambientais considerados; 5- Identificação do processo/ função a ser considerado; 6- Identificação dos aspectos e impactos ambientais; 7- Identificação das causas e falhas; 8- Identificação dos controles atuais de deteç̧ão; 9- Determinação dos índices de criticidade; 10- Análise dos riscos ambientais e plano de ações; 11- Revisão do plano de ação; e 12- Revisão do FMEA, sempre que necessário.

O método proposto por Andrade (2000) contempla o processo prático do FMEA, especificadamente nas etapas 5, 6, 7, 8, 9, que, uma vez aplicadas, resultam em um formulário de análise estruturado em nove colunas, conforme apresentado no Quadro 2. A primeira coluna corresponde à etapa de identificação do processo/função, descrevendo de forma direta o processo e/ou a função em que serão analisados os impactos ambientais. A segunda e a terceira coluna correspondem respectivamente à etapa de identificação dos aspectos e impactos ambientais associados ao processo/função. A quarta coluna corresponde ao índice de gravidade do impacto (G). Segundo Vandenbrande (1998), este resulta de uma análise do efeito do risco para a avaliação de sua gravidade, que é estimado em uma escala de 1 a 10, conforme o Quadro 2. 


\begin{tabular}{|c|c|c|c|c|c|c|c|c|}
\hline 1 & 2 & 3 & 4 & 5 & 6 & 7 & 8 & 9 \\
\hline $\begin{array}{l}\text { Etapa do } \\
\text { processo }\end{array}$ & $\begin{array}{c}\text { Aspectos } \\
\text { ambientais }\end{array}$ & $\begin{array}{l}\text { Impactos } \\
\text { ambientais }\end{array}$ & $\begin{array}{c}\text { Gravidade } \\
\text { do impacto } \\
\text { (G) }\end{array}$ & $\begin{array}{c}\text { Causa } \\
\text { potencial }\end{array}$ & $\begin{array}{c}\text { Ocorrência } \\
\text { da causa } \\
\text { (0) }\end{array}$ & $\begin{array}{c}\text { Forma } \\
\text { atual de } \\
\text { controle }\end{array}$ & $\begin{array}{l}\text { Grau de } \\
\text { detecção } \\
\text { (D) }\end{array}$ & IRA \\
\hline
\end{tabular}

Quadro 2 - Modelo em colunas de um formulário de análise com base no método FMEA.

Fonte: elaborado a partir de Andrade (2000).

A etapa da identificação das causas e falhas, contemplada na quinta coluna, refere-se às causas potenciais de falhas, descritas em termos de algo que se possa corrigir ou controlar, e, relacionada a esta, a sexta coluna apresenta o índice de ocorrência de causa (O). Este índice parte de uma análise do efeito do risco para a avaliação de sua probabilidade de ocorrência, que é estimado também em uma escala de 1 a 10, conforme o Quadro 2. Resumindo, o índice de ocorrência de causa aborda a probabilidade de ocorrência de uma causa/mecanismo específico.

Na sétima coluna, estão os controles atuais do processo/função que foram diagnosticados na etapa de identificação dos controles atuais de deteç̧ão das falhas ou causas. Em sequência, a oitava coluna mostra o grau de detecção (D), que parte da avaliação de uma causa do risco, exprimindo o grau de controle possível de ser exercido sobre ele. Como os demais índices já apresentados, ele é estimado em uma escala de 1 a 10, conforme o Quadro 3, e refere-se à capacidade de controle e atuação no processo para evitar ou minimizar as causas do risco.

No que tange à nona coluna, ela mostra o Índice de Risco Ambiental (IRA), que é a multiplicação dos valores estimados para cada um dos três índices anteriores $(G, O$ e $D)$. Esse índice propicia uma escala hierárquica da relevância de cada processo/função e seus respectivos impactos.

A quarta, sexta, oitava e nona colunas são resultados da etapa de determinação dos índices de criticidade.

\begin{tabular}{|c|c|}
\hline Gravidade do impacto & Índice \\
\hline Dificilmente será visível. Muito baixa para ocasionar um impacto no meio ambiente. & $1-2$ \\
\hline Não conformidade com a política da empresa. Impacto baixo ou muito baixo sobre o meio ambiente. & $3-4$ \\
\hline Não conformidade com os requisitos legais e normativos. Potencial de prejuízo moderado ao meio ambiente. & $5-6$ \\
\hline Sério prejuízo à saúde das pessoas envolvidas nas tarefas. & $7-8$ \\
\hline Há sérios riscos ao meio ambiente. & $9-10$ \\
\hline \multicolumn{2}{|l|}{ Ocorrência da causa } \\
\hline Remota: é altamente improvável que ocorra. & $1-2$ \\
\hline Baixa: ocorrência em casos isolados e com baixa probabilidade de ocorrer em um semestre. & $3-4$ \\
\hline Moderada: tem probabilidade razoável de ocorrer em um semestre. & $5-6$ \\
\hline Alta: ocorre com regularidade e/ou com períodos razoáveis de tempo, mais de uma vez por semestre. & $7-8$ \\
\hline $\begin{array}{l}\text { Muito alta: não se tem como evitar, ocorre durante longos períodos típicos para condições opera- } \\
\text { cionais. Grande probabilidade de ocorrer cada vez que executada a atividade. }\end{array}$ & $9-10$ \\
\hline \multicolumn{2}{|l|}{ Grau de detecção } \\
\hline $\begin{array}{l}\text { Os controles atuais irão detectar quase de imediato o aspecto, e a reação pode ser instantânea. } \\
\text { Detecção rápida e solução rápida. }\end{array}$ & $1-2$ \\
\hline $\begin{array}{l}\text { Existe alta probabilidade de que o aspecto seja detectado logo após a sua ocorrência, sendo pos- } \\
\text { sível uma rápida reação/detecção em médio prazo e solução rápida. }\end{array}$ & $3-4$ \\
\hline $\begin{array}{l}\text { Há uma probabilidade moderada de que o aspecto seja detectado em um período razoável de } \\
\text { tempo antes que uma ação possa ser tomada e os possam ser resultados vistos. Detecção e solu- } \\
\text { ção em médio prazo. }\end{array}$ & $5-6$ \\
\hline $\begin{array}{l}\text { É improvável que o aspecto seja detectado ou levará um período razoável de tempo antes que } \\
\text { uma ação possa ser tomada e os resultados sejam vistos. Detecção em médio prazo e solução em } \\
\text { longo prazo. }\end{array}$ & $7-8$ \\
\hline $\begin{array}{l}\text { O aspecto não será detectado em nenhum período razoável de } \\
\text { Detecção em longo prazo e solução em longo prazo. }\end{array}$ & $9-10$ \\
\hline
\end{tabular}

Quadro 3 - Diretrizes para classificação dos índices de criticidade.

Fonte: Vandenbrande (1998). 
A proposta de Vandenbrande (1998) e o trabalho de Andrade (2000) serviram de inspiração e embasamento para diversos estudos no contexto brasileiro no que tange a setores e atividades econômicas geradoras de impactos ambientais significativos. Martins e Zambrano (2003) utilizaram a metodologia FMEA para a análise dos impactos ambientais em uma empresa do ramo de usinagem. Para tanto, os autores realizaram um levantamento das entradas e saídas de cada operação do processo de usinagem do pino de pistão e, posteriormente, calcularam para cada resíduo e efluente o risco ambiental através da multiplicação dos índices adotados para a severidade do impacto ambiental, a probabilidade de ocorrência e a facilidade de detecção. Como resultado, pode-se destacar que o maior risco ambiental no contexto estudado foi o óleo desperdiçado, porque, durante o processo de torneamento e furação, as gotas de óleo expelidas não retornavam ao processo, mas aderiam ao chão da fábrica, causando uma série de riscos, incluindo-se a contaminação humana.

Nessa mesma linha, Coimbra (2003) e Silva (2003) utilizaram o FMEA em suas dissertações para a avaliação de significância de aspectos e impactos ambientais na indústria de cerâmica e os impactos e custos ambientais em processos industriais, respectivamente.

Oliveira e Freitas (2011) buscaram, via FMEA, avaliar os aspectos e impactos ambientais em uma indústria de microeletrônica localizada na cidade de Campina Grande (PB). A contribuição dada por tais autores reside na demonstração da viabilidade do uso da ferramenta FMEA para a análise dos aspectos e impactos ambientais da indústria, devido ao seu formato possibilitar a integração, em uma só ferramenta, da descrição dos processos e de seus respectivos aspectos e impactos, mensurando-os e definindo as práticas a serem utilizadas em cada caso específico.

Junior et al. (2011) ampliaram a aplicação do FMEA ao usá-la no âmbito de uma instituição de ensino para analisar os respectivos impactos por ela gerados. O objetivo foi levantar quais os impactos ambientais gerados no Instituto Federal de Educação, Ciência e Tecnologia de Mato Grosso, Campus Cuiabá - Bela Vista. O estudo mostrou que, com a ferramenta, é possível apontar uma ordem de prioridade dos impactos ambientais, podendo ser reaplicada, caso sejam tomadas as medidas para mitigar esses impactos, a fim de alcançar um melhor desempenho ambiental da instituição, principalmente no que diz respeito à geração dos resíduos laboratoriais, ao consumo de água nos laboratórios, ao investimento na educação ambiental dos frequentadores e da comunidade acadêmica do campus, à geração de resíduos sólidos nas salas técnico-administrativas e à redução do consumo da energia elétrica em todos os ambientes.

Por fim, outro trabalho relevante quanto à aplicabilidade do FMEA foi o realizado por Wenceslau e Rocha (2012), que objetivou utilizar o FMEA como suporte para a identificação dos aspectos e impactos ambientais em uma agroindústria de arroz. Esse estudo mostrou que, de maneira geral, os levantamentos realizados não apresentaram problemas ambientais graves nem sérios comprometimentos à saúde dos funcionários. O que se pode observar é que alguns investimentos são necessários para a melhoria da eficiência do processo produtivo neste contexto.

Diante do exposto, verifica-se a crescente utilização do FMEA como ferramenta de avaliação de aspectos e impactos ambientais e sua consequente aplicabilidade e contribuição para os diferentes setores. Contudo, tendo em vista o instrumento apresentado e uma vez explicitados os fundamentos teóricos que nortearão o estudo por apresentarem a viabilidade da aplicação do FMEA no que tange à avaliação de aspectos e impactos ambientais, em seguida, apresentam-se os aspectos metodológicos utilizados nesta pesquisa. 


\section{METODOLOGIA}

Diante do objetivo proposto de identificar e analisar os potenciais impactos ambientais causados pelas atividades desenvolvidas em um posto de distribuição de combustíveis, à luz do método FMEA, o presente trabalho caracteriza-se como exploratório e descritivo. É exploratório uma vez que permite conhecer os fatos e fenômenos relacionados ao tema de estudo e, segundo Gil (1996), tem como principal finalidade desenvolver, esclarecer e modificar conceitos e ideias com vistas à formulação de um problema para estudo. Cabe destacar que a referida pesquisa se caracteriza, também, como exploratória, já que transita por um tema ainda em construção e que conta com um número relativamente baixo de trabalhos realizados na área. É descritiva por fazer um levantamento das características conhecidas acerca dos componentes do fato/fenômeno/ processo e por ter como objetivo, conforme apresentado por Marconi e Lakatos (1999), descrever, registrar, analisar e interpretar os fenômenos atuais.

Como método de pesquisa, utiliza-se o estudo de caso, sendo o Posto Alfa o caso escoIhido. Segundo Yin (2005), o estudo de caso é uma forma de fazer pesquisa investigativa de fenômenos atuais dentro de seu contexto real, em situações em que as fronteiras entre o fenômeno e o contexto não estão claramente estabelecidos. Contudo, Eisenhardt (1989) complementa que os estudos de casos podem envolver como recursos para a coleta de dados a análise de arquivos, a realização de entrevistas, a aplicação de questionários e a observação.

Para tanto, o presente trabalho utilizou-se de dados primários e secundários. Para a coleta de dados em fontes primárias, optou-se pelo uso de entrevista semiestruturada e de observação não participante. No que tange à entrevista, esta foi realizada com os seguintes atores, contemplando as respectivas informações requeridas para o estudo: o proprietário, acerca do ramo de atividade e da importância das questões ambientais na empresa, já que este esteve presente deste o planejamento e a implantação do empreendimento; o gerente administrativo, a respeito do conhecimento dos impactos causados pela atividade, da política de gestão dos aspectos ambientais, das práticas da empresa e da gestão de resíduos; os três frentistas, as duas cozinheiras do restaurante e as três vendedoras da loja de conveniência e artesanato, sobre os aspectos operacionais das atividades desempenhadas e a conformidade destas com possível política de gestão ambiental da empresa. No que tange às entrevistas, destaca-se, ainda, o fato de que o conteúdo obtido foi utilizado na descrição das atividades desenvolvidas pela empresa e na identificação dos potenciais impactos causados por estas, conforme o disposto na análise dos dados.

Quanto à observação não participante, esta foi escolhida como técnica devido ao fato de possibilitar a identificação in loco de fatores importantes para o estudo, tais como: ambiente físico e instalações do empreendimento, resíduos gerados pelas atividades desenvolvidas, gerenciamento dos resíduos, atitudes que podem gerar risco de incêndios, comportamento dos frentistas, possíveis vazamentos etc. Vale a pena salientar que a observação não participante, para Yin (2005), é uma modalidade de observação em que o pesquisador não assume uma postura ativa e participativa nos eventos que estão sendo estudados. Nesse sentido, foram feitas quatro visitas ao estabelecimento, com duração média de cinco horas cada, e a coleta de dados ocorreu no período de 19/01/2011 a 31/03/2011. Já para a coleta de dados em fontes secundárias, foram utilizados: relatórios, artigos e estudos realizados no ramo dos postos de combustíveis, além de documentos, relatórios resultantes de fiscalização existentes na empresa, licenças ambientais, dentre outros.

$\mathrm{Na}$ análise dos dados, o procedimento adotado foi qualitativo para o entendimento e a caracterização de todo o estudo de caso e quantitativo para a mensuração dada pelos índices de criticidade apresentados no método FMEA. Nesse sentido, o presente estudo adotou a meto- 
dologia proposta por Andrade (2000), a qual contempla o processo prático do FMEA, especificadamente nas etapas 5, 6, 7, 8, e 9. Devido à amplitude desse instrumento e ao foco do presente estudo, procedeu-se à aplicação dessas cinco etapas.

Importa salientar que na nona etapa são calculados os índices de criticidade, que permitem avaliar a gravidade e a ocorrência de detecção do impacto, bem como classificá-los, por meio do Índice de Risco Ambiental (IRA) quanto ao risco destes na realização das respectivas atividades relacionadas. Para tanto, utilizou-se a multiplicação da variação máxima e mínima dos três índices ( $G, O$ e $D)$, que determinam se o risco é muito baixo, baixo, médio, alto ou muito alto, conforme apresenta o Quadro 4.

\begin{tabular}{|c|c|c|c|}
\hline Risco & Variação do G, O e D & Multiplicação dos índices & Variação do IRA \\
\hline Muito Baixo & $1-2$ & $(1 \times 1 \times 1)-(2 \times 2 \times 2)$ & $1-8$ \\
\hline Baixo & $3-4$ & $(3 \times 3 \times 3)-(4 \times 4 \times 4)$ & $9-56$ \\
\hline Médio & $5-6$ & $(5 \times 5 \times 5)-(6 \times 6 \times 6)$ & $57-216$ \\
\hline Alto & $7-8$ & $(7 \times 7 \times 7)-(8 \times 8 \times 8)$ & $217-512$ \\
\hline Muito Alto & $9-10$ & $(9 \times 9 \times 9)-(10 \times 10 \times 10)$ & $513-1.000$ \\
\hline
\end{tabular}

Quadro 4 - Escala de Variação do IRA.

Fonte: adaptado de Vandenbrande (1998).

Com base no Quadro 4, pode-se afirmar que um impacto ambiental que tenha um IRA entre 1 e 8 é um impacto cujo risco é muito baixo, quase insignificante. Por outro lado, o impacto cujo IRA estiver entre 513 e1.000 é de risco muito alto, ou seja, de gravidade e ocorrência muito altas, e dificilmente será detectado.

Uma vez explicitados os aspectos metodológicos que deram suporte à pesquisa, a seguir, serão apresentados e analisados os dados obtidos.

\section{ANÁLISE DOS RESULTADOS}

\subsection{A empresa e suas atividades}

A empresa objeto do estudo é um posto de combustível, aqui identificado como Posto Alfa, a fim de preservar a identidade da organização. Este se localiza na zona rural do município de Pocinhos (PB) e caracteriza-se como um comércio varejista de combustíveis (óleo diesel, gasolina e álcool), serviços de restaurante, loja de conveniência e artesanato, consistindo estas duas últimas atividades apenas na revenda de produtos. O posto conta com quatro bombas de abastecimento e três tanques ecológicos de armazenamento de combustíveis. A organização possui dois sócios que atuam no gerenciamento do negócio.

A empresa exibe a bandeira Ello-Puma, emprega diretamente 14 pessoas e comercializa uma média mensal de 35.000 litros de gasolina, 8.000 litros de álcool e 15.000 litros de óleo diesel. Seus clientes-alvo são viajantes que, de passagem pela região, normalmente são atraídos pela localização, pela comodidade e pelo preço. O Posto Alfa deu início às suas atividades em 3 de setembro de 2007, depois de ser adquirido no final de 2005 em um leilão. No ano seguinte, passou por legalização e reforma, que consistiram na retirada de tanques antigos de armazenamento, na construção de tanques ecológicos de PVC, na ampliação da pista de abastecimento, na construção das instalações de restaurante e lojas, bem como na aquisição de licenças necessárias.

No que tange às questões de cunho ambiental, o posto atende às conformidades legais, tais como: licença prévia (LP), que estabelece alguns requisitos para o processo de instalação de um 
posto; licença de instalação (LI), que autoriza a instalação do empreendimento depois de projetos aprovados com normas e controles ambientais; e licença de operação (LO), que autoriza a operação da atividade, depois de liberadas as licenças anteriores, com as medidas de controle ambiental.

Quanto às atividades desenvolvidas pela empresa, foram identificadas: recebimento/armazenamento de combustíveis, abastecimento de veículos, preparação/serviço de alimentos (restaurante), comercialização de produtos (lojas de conveniência e artesanato), atividades administrativas e lavagem/ manutenção de banheiros. A fim de uma melhor compreensão de como e em que condições são realizadas essas atividades, faz-se necessária uma breve descrição de cada uma, que será feita a seguir.

\section{a) Recebimento de combustiveis}

Todo combustível comercializado na empresa é de distribuição da Ello-Puma, responsável pela qualidade e pela segurança, desde a produção dos combustíveis até a sua distribuição. É a distribuidora que garante as condições ideais de manipulação, deslocamento e descarga dos seus produtos no estabelecimento. Conforme as informações obtidas, a empresa estudada adota as seguintes medidas na atividade de recebimento: preparação para a descarga do produto e conferência. A preparação de descarga do produto consiste na solicitação feita pelo gerente do Posto Alfa para que o motorista do caminhão-tanque estacione em superfície plana e horizontal e apresente a nota fiscal e o certificado de aferição do tanque do caminhão. Feito isso, o solicitante executa os seguintes procedimentos: verifica a licença do caminhão-tanque (placa), observando se é a mesma que consta na nota fiscal e no certificado de aferição; observa o produto no tanque para saber se realmente é o combustível pedido pela empresa; confere se a quantidade de combustível constante na nota fiscal é compatível com a capacidade do caminhão-tanque, registrada no certificado de aferição; e, por último, confere o estado dos lacres existentes nas válvulas de descarga e nas bocas de enchimento. Em seguida, uma amostra do combustivel é retirada através da válvula de descarga e colocada em uma proveta de $1000 \mathrm{ml}$, onde é feita a verificação a olho nu da coloração e da presença de água e/ou outras substâncias estranhas. Caso seja constatada alguma irregularidade no produto, este é recusado; caso contrário, é feita a descarga nos tanques de armazenamento. A descarga selada é o método utilizado pela empresa.

\section{b) Armazenamento de combustiveis}

A empresa possui três tanques ecológicos de armazenamento de combustíveis. Os tanques ecológicos são, por regulamentação, constituídos de PVC, possuindo capacidade individual de armazenar 30 mil litros de combustível. Na empresa, os três tanques possuem subdivisão, tendo cada uma destas a capacidade de armazenar 15 mil litros. Os tanques são dispostos da seguinte forma: o primeiro armazena gasolina comum e gasolina aditivada; o segundo, álcool e gasolina comum; e o terceiro, apenas óleo diesel.

\section{c) Abastecimento dos veículos}

A pista de abastecimento é totalmente coberta e dispõe de piso impermeável e canaletas em seu entorno, além de contar com quatro bombas eletrônicas de abastecimento: duas abastecem gasolina comum, uma álcool, uma gasolina aditivada e a última, óleo diesel. Os procedimentos ocorrem da seguinte forma: o frentista acena para o cliente e indica o local adequado para o abastecimento, buscando sempre usar a última bomba disponível no sentido do fluxo de 
veículos. Em seguida, orienta o cliente a parar e desligar o veículo, durando essa operação, em média, cinco segundos. Feito isso, o abastecimento é realizado conforme o solicitado pelo cliente.

\section{d) Preparação/serviço de alimentos (restaurante)}

O restaurante conta com ampla e boa estrutura física, variedade e qualidade dos serviços e alimentos dispostos em cardápio, além de boa higiene no local. No que diz respeito à preparação dos alimentos, o restaurante conta com duas cozinheiras e três ajudantes que auxiliam nesse processo e atuam como garçons, além de ser também responsáveis pelo abastecimento das bandejas dos balcões térmicos, onde ficam dispostos os alimentos para os clientes. Quanto ao serviço, deve-se destacar que é self-service, fornecendo refeições diárias (café, almoço e jantar) e chegando a servir uma média de 150 refeições por dia.

\section{e) Comercialização de produtos}

Essa atividade é desenvolvida nas lojas de conveniência e artesanato. A loja de conveniência consiste em um pequeno estabelecimento comercial, não franqueado, onde são realizadas vendas diretas de diversos produtos do gênero alimentício, tais como: refrigerantes, biscoitos, salgadinhos, balas, dentre outros. Os procedimentos operacionais restringem-se ao atendimento ao cliente, ao gerenciamento de estoque, à limpeza do local e ao atendimento no caixa. Quanto às lojas de artesanato, estas se dividem em dois espaços, sendo um destinado a presentes e artigos de decoração e o outro à venda de móveis rústicos. Os procedimentos operacionais são os mesmos praticados na conveniência. Vale salientar que nestas lojas trabalham três funcionárias, contratadas do Posto Alfa, e que se revezam na realização das atividades.

\section{f) Lavagem e manutenção dos banheiros}

Embora sejam desempenhados procedimentos simples, é preciso manusear os produtos de limpeza utilizados com cuidado para evitar contaminação. Observou-se que a limpeza dos banheiros é feita duas vezes ao dia e que o funcionário encarregado usa luvas, botas e máscaras.

Uma vez apresentada a empresa estudada e descritas suas atividades, a seguir, é feita uma identificação e análise dos potenciais impactos ambientais causados por tais atividades.

\subsection{Identificações dos potenciais impactos causados pelas atividades desenvolvidas no Posto Alfa}

Considerando os tipos de impactos ambientais causados pelos postos de combustíveis e sua classificação nas categorias contaminação humana, contaminação do solo e águas subterrâneas, incêndio e resíduos, de acordo com Rocha et al. (2004), o presente estudo identificou em cada atividade desenvolvida os potencias impactos ocasionados, os quais serão apresentados a seguir.

\section{a) Contaminação humana}

Pode ser causada pela inalação, pelo contato direto com a pele ou pela ingestão, ocasionando o aparecimento de dermatites, conjuntivites, dor de cabeça, sonolência, tontura, náuseas, gastrites e infecções. As atividades que podem potencialmente ocasionar tal impacto são as de recebimento e armazenamento de combustíveis, abastecimento, preparação/serviços de alimentos e lavagem de banheiros. 
No caso das atividades que envolvem contato direto com gasolina, álcool e diesel, como o recebimento, armazenamento e abastecimento, os funcionários ficam expostos a emissões gasosas, bem como a componentes químicos que agridem os olhos e a pele. No caso estudado, identificou-se que frentistas já apresentaram tontura, fortes dores de cabeça e leves dermatites. A empresa encaminhou-os para a realização de exames, que diagnosticaram a exposição aos combustiveis como causa dos sintomas. Durante a pesquisa, observou-se que, no recebimento e armazenamento, há cuidados por parte da empresa em realizar o procedimento de análise da amostra de combustíveis e descarga do mesmo utilizando Equipamentos de Proteção Individual (EPI's), que são respirador e luva. No entanto, durante o abastecimento, apesar de a empresa disponibilizar os EPI's, os frentistas não utilizam nenhum desses equipamentos de proteção.

No que diz respeito à contaminação humana no preparo e serviços dos alimentos, este risco não é tão expressivo para aqueles que manipulam e servem os alimentos, mas sim para aqueles que vão consumi-los. Para tanto, confere-se maior atenção às condições de preparação dos alimentos, uma vez que as cozinheiras trabalham devidamente fardadas, utilizando avental, luvas, tocas e botas durante o processo. As superfícies que entram em contato com os alimentos, como bancadas e mesas, são mantidas em bom estado de conservação, sem rachaduras, trincas ou outros defeitos. No entanto, não se observou nos ajudantes o uso de fardamento padronizado nem a utilização de luvas e aventais, o que pode servir de via para contaminação dos alimentos.

Quanto ao serviço, destaca-se que, por se tratar de um restaurante self-service, é preciso levar em consideração, além das condições de abastecimento das bandejas, a disponibilidade de material para higienização por parte dos clientes, bem como a disposição dos talheres, copos e pratos. No que tange à higienização pessoal, o restaurante possui pias bem localizadas, equipadas com detergente e papel toalha; quanto aos talheres e pratos, são dispostos em uma bancada sobre a qual ficam organizados em um compartimento fechado; já copos e pratos ficam expostos.

$\mathrm{Na}$ atividade de lavagem de banheiros, considera-se o impacto em questão por ser uma atividade que expõe o trabalhador a um ambiente que contém grande quantidade de bactérias e parasitas, principalmente por se tratar de um banheiro de acesso público e de grande fluxo de pessoas. As bactérias e os parasitas, quando em contato com a pele, podem entrar no organismo e provocar diarreia, dor abdominal, vômito, anemia, dentre outros problemas. Para prevenir e minimizar esse impacto, os encarregados dessa atividade fazem uso de luvas, botas e máscaras durante a limpeza. Entretanto, não utilizam aventais ou capas de proteção para evitar contato com o fardamento, que será usado durante todo o expediente.

\section{b) Contaminação do solo e da água subterrânea}

As atividades que exprimem este potencial impacto são: recebimento/armazenamento de veículos; abastecimento; preparação/serviços de alimentos; e lavagem/manutenção dos banheiros. Nas atividades que envolvem combustíveis, a contaminação é causada pela ocorrência de vazamentos nos tanques de armazenamento e bombas de abastecimento.

Os vazamentos de combustíveis geram, como impacto específico no solo, a degradação, que está ligada a alterações nas características químicas, visto que os hidrocarbonetos presentes nos combustíveis podem ocasionar a perda da "saúde" e qualidade do solo, as quais, por sua vez, estão relacionadas aos teores adequados de matéria orgânica que são alterados pela presença destes componentes químicos. No caso das águas subterrâneas, uma vez contaminadas, ficam impróprias para o uso, já que os hidrocarbonetos presentes na gasolina, no álcool e no óleo diesel possuem substâncias tóxicas que são facilmente dissolvidas na água. Tais impactos colocam em risco a 
saúde da população entorno do posto se houver ingestão ou contato com tais substâncias, pois a gasolina é composta por benzeno, etilbenzeno, tolueno e xileno, que são substâncias cancerígenas.

No caso estudado, o Posto Alfa possui tanques ecológicos com válvulas que previnem o vazamento. Além de seguir a norma estabelecida por lei, a empresa faz semestralmente o monitoramento da qualidade do solo e das águas da área pela qual esta é responsável. No que tange à atividade de recebimento que inclui a descarga do combustível, a empresa adota o procedimento de descarga selada, por ser um procedimento seguro. No abastecimento, as bombas são automatizadas. Isso quer dizer que, quando se chega à litragem de combustível programada, automaticamente o abastecimento é cortado, e, em seguida, o frentista utiliza uma flanela para limpar o bico da bomba, evitando, assim, que, ao término do abastecimento, gotas de combustível caiam sobre o veículo ou sobre o piso da pista. Caso ocorra vazamento, o piso já é impermeabilizado para que o líquido escorra em direção às caneletas de contenção e, de lá, para uma caixa separadora de água e óleo.

Além da contaminação ocasionada pelo vazamento de combustíveis, existe a contaminação por efluentes líquidos e resíduos gerados nas atividades de preparação/serviço dos alimentos e limpeza/manutenção dos banheiros, as quais serão especificadas no que se refere aos impactos de resíduos.

\section{c) Incêndio}

As atividades que geram risco de incêndio são o recebimento e armazenamento de combustíveis (em que o risco está presente pelo manuseio de combustíveis, que são por natureza inflamáveis), o abastecimento de veículos e a preparação dos alimentos. Os impactos específicos causados por incêndio são consequências da sua ocorrência, ou seja, danos materiais/perda das instalações; risco à saúde/vida de funcionários, clientes e moradores vizinhos e riscos ao meio ambiente, visto que as chamas podem se espalhar pela vegetação ao redor do empreendimento, gerando danos ao solo, além de a fumaça tóxica - oriunda da combustão - poluir o ar. Para que não ocorram, estes impactos devem ser prevenidos por meio de cuidados e condutas de segurança, pois os principais causadores de incêndio são eventuais derrames de combustíveis que, em contato com o fogo ou por eletricidade estática, podem ocasionar explosão.

O Posto Alfa está em conformidade legal com as normas que estabelecem os procedimentos de segurança a serem adotados por este ramo de atividade e toma as seguintes precauções: durante o recebimento e armazenamento de combustíveis, por segurança, é solicitado ao motorista a colocação dos cones de isolamento, extintor de incêndio e placas de sinalização "PERIGO AFASTE-SE" e/ou "PERIGO NÃO FUME"; no que se refere à conferência do produto, retira-se uma amostra deste somente após a ligação do cabo terra (primeiro na boca do tanque, em terra, e depois no caminhão tanque) e após a colocação da mangueira de descarga; quanto aos aspectos gerais, disponibiliza extintores de incêndio na pista em local visível e sinalizado, possui fio de descarga de eletricidade estática e, durante o abastecimento, proíbe-se o uso de celular na pista. Contudo, durante a pesquisa, observou-se que um dos funcionários estava com o celular em uso na pista de abastecimento, o que pode servir como condutor de eletricidade estática e gerar acidentes. Vale ressaltar, também, que, em caso de acidentes desta natureza, a empresa não possui um programa de treinamento que deixe seus funcionários aptos a agir.

Quanto ao preparo dos alimentos, o risco de incêndio está atrelado à presença de uma fonte de calor associada a elementos de fácil combustão, como gordura, óleo e gás de cozinha, que, ao inflamar, pode permitir o alastramento do incêndio, atingindo equipamentos, dutos ou mesmo a totalidade das instalações. Deve-se ressaltar que, por se tratar de uma cozinha industrial, muitos 
dos equipamentos funcionam à base de energia elétrica. Sendo assim, as condições da rede elétrica e dos fios devem ser observadas a fim de evitar curtos-circuitos. Para a prevenção, o restaurante conta com seis extintores, distribuídos entre a cozinha e a área de alimentação, possui instalações elétricas em bom estado de conservação e dispõe de placas de sinalização que indicam áreas de risco na cozinha e alertam para verificação de possível vazamento de gás. O restaurante é instalado no interior do Posto Alfa; por esse motivo, o cuidado é redobrado, pois, caso ali ocorra algum acidente, pode pôr em risco toda a estrutura do posto devido aos combustíveis ali comercializados.

\section{c) Resíduos}

Das atividades desenvolvidas no Posto Alfa, as únicas que não geram resíduos expressivos são as de recebimento e armazenamento de combustíveis. No abastecimento de veículos, os resíduos gerados são flanelas utilizadas durante o abastecimento para limpar o bico da bomba e efluentes líquidos oriundos da limpeza de vidro de carros. As flanelas, por manterem contato direto com os combustíveis, são resíduos considerados tóxicos que podem ser geradores de impactos de contaminação humana e incêndio. Para evitar danos, elas são recolhidas por uma empresa especializada no tratamento desses resíduos. No se refere aos efluentes líquidos, estes são lançados em esgoto comum.

Os resíduos gerados na atividade de preparação/serviço de alimentos são: óleo de cozinha; resíduos orgânicos oriundos da preparação dos alimentos; restos de comida do prato de clientes; luvas e toucas cirúrgicas; embalagens de papel, plástico, metal e pet; efluentes líquidos; e emissões gasosas. O óleo de cozinha é armazenado em latas de metal e, posteriormente, é vendido para uma recicladora localizada em Campina Grande (PB). Quanto aos demais resíduos sólidos, são destinados sem nenhuma separação para coleta da prefeitura e, por conseguinte, enviados aos lixões. No que tange aos efluentes líquidos, são tratados e lançados em esgoto comum. Cabe destacar que, caso estes resíduos não fossem destinados corretamente, alguns levariam anos e até mesmo décadas para se decompor no meio ambiente.

Sobre os resíduos gerados na comercialização de produtos, que é o caso das lojas de conveniência e artesanato, foram verificados: embalagens de plástico e papel, copos descartáveis, garrafas pet e latas, além do lixo comum. As atividades administrativas também geram como resíduos papel, copos descartáveis e lixo comum. Estes são destinados sem separação para a coleta da prefeitura.

Por fim, na lavagem/manutenção dos banheiros, destacaram-se como resíduos: papel higiênico pós-uso, efluentes líquidos e embalagem de detergentes usados na limpeza. A destinação destes é a mesma dos resíduos citados nos casos anteriores.

Tendo em vista a identificação dos impactos causados pelas atividades desenvolvidas no Posto Alfa, faz-se, a seguir, uma análise à luz do FMEA.

\subsection{Análise dos impactos causados pelas atividades desenvolvidas no Posto Alfa à luz do FMEA}

Com base nos dados obtidos sobre as atividades realizadas no Posto Alfa e seus respectivos impactos, gerou-se um formulário do FMEA para uma análise quantitativa destes. Nesse sentido, o formulário evidencia as atividades desempenhadas pelo Posto Alfa; os aspectos ambientais relevantes de cada atividade; o impacto gerado; a potencial causa e as formas de controle atuais adotadas pela empresa. A análise quantitativa é feita por meio dos índices de criticidade: Gravidade do impacto (G), Ocorrência da causa (O), Grau de detecção (D) e Índice de Risco Ambiental (IRA), conforme o referenciado por Vandenbrande (1998). 
Para tanto, o formulário aplicado (ver Quadro 5) apresenta, de forma simplificada, a análise dos impactos ambientais causados pelas atividades desenvolvidas no Posto Alfa, baseando-se na classificação destes feita por Rocha et al. (2004). Nesse sentido, para cada atividade são analisados os impactos de contaminação humana; contaminação do solo e da água subterrânea; incêndio e resíduos, se presentes. Vale a pena salientar que, para cada tipo de impacto identificado na atividade-foco, é apresentado um IRA, que é resultante do somatório dos índices de criticidade que são atribuídos a cada tipo de impacto na atividade-foco. Destaca-se o fato de que a atribuição dos índices de criticidade é dada pelo pesquisador com base nas informações obtidas na coleta de dados. Sendo assim, tendo-se o IRA, este é enquadrado na seguinte classificação quanto ao risco ambiental: entre 1 e8 - muito baixo (MB), 9 e 56 - baixo (B), 57 e 216 - médio (M), 217 e 512 - alto (A) e 513 e 1.000 -muito alto (MA).

\begin{tabular}{|c|c|c|c|c|c|c|c|c|}
\hline $\begin{array}{c}\text { Atividades } \\
\text { desenvolvidas }\end{array}$ & $\begin{array}{c}\text { Aspectos } \\
\text { ambientais }\end{array}$ & Impactos & G & Causa Potencial & $\mathrm{O}$ & $\begin{array}{l}\text { Forma atual } \\
\text { de controle }\end{array}$ & $\mathrm{D}$ & IRA \\
\hline \multirow[t]{3}{*}{$\begin{array}{l}\text { Recebimento/ } \\
\text { armazenamento }\end{array}$} & \multirow{3}{*}{$\begin{array}{l}\text { Qualidade do } \\
\text { solo, do ar e } \\
\text { das águas. } \\
\text { Saúde do tra- } \\
\text { balhador. }\end{array}$} & $\begin{array}{l}\text { Cont. } \\
\text { humana. }\end{array}$ & 7 & $\begin{array}{l}\text { Contato direto } \\
\text { com os combus- } \\
\text { tíveis. }\end{array}$ & 3 & $\begin{array}{l}\text { Fornecimento de } \\
\text { EPI's. }\end{array}$ & 4 & $\begin{array}{l}84 \\
M\end{array}$ \\
\hline & & $\begin{array}{l}\text { Cont. água } \\
\text { e solo. }\end{array}$ & 10 & Vazamentos. & 1 & $\begin{array}{l}\text { Verificação semestral } \\
\text { da qualidade do solo e } \\
\text { da água. Tanques eco- } \\
\text { lógicos com válvulas. }\end{array}$ & 5 & $\begin{array}{c}50 \\
\text { B }\end{array}$ \\
\hline & & Incêndio. & 8 & $\begin{array}{l}\text { Vazamentos, } \\
\text { eletricidade es- } \\
\text { tática e presença } \\
\text { de fogo. }\end{array}$ & 5 & $\begin{array}{l}\text { Placas de sinaliza- } \\
\text { ção em conformi- } \\
\text { dade legal com nor- } \\
\text { mas de segurança. }\end{array}$ & 2 & $\begin{array}{l}80 \\
M\end{array}$ \\
\hline \multirow[t]{4}{*}{ Abastecimento } & \multirow{4}{*}{$\begin{array}{l}\text { Qualidade do } \\
\text { ar. } \\
\text { Geração de re- } \\
\text { síduos. } \\
\text { Saúde do tra- } \\
\text { balhador. }\end{array}$} & $\begin{array}{l}\text { Cont. } \\
\text { humana. }\end{array}$ & 7 & $\begin{array}{l}\text { Contato direto } \\
\text { com os combus- } \\
\text { tíveis. }\end{array}$ & 9 & $\begin{array}{l}\text { Fornecimento de } \\
\text { EPI's. }\end{array}$ & 4 & $\begin{array}{c}252 \\
\text { A }\end{array}$ \\
\hline & & $\begin{array}{l}\text { Cont. água } \\
\text { e solo }\end{array}$ & 10 & Vazamentos. & 3 & $\begin{array}{l}\text { Uso de flanela e } \\
\text { bombas automati- } \\
\text { zadas. }\end{array}$ & 1 & $\begin{array}{c}30 \\
\text { B }\end{array}$ \\
\hline & & $\begin{array}{l}\text { Resíduos } \\
\text { tóxicos. }\end{array}$ & 6 & $\begin{array}{l}\text { Descarte inade- } \\
\text { quado. }\end{array}$ & 5 & $\begin{array}{l}\text { Coletado por em- } \\
\text { presa especializada. }\end{array}$ & 1 & $\begin{array}{c}30 \\
\mathbf{B}\end{array}$ \\
\hline & & Incêndio. & 8 & & 5 & $\begin{array}{l}\text { Placas de sinaliza- } \\
\text { ção em conformida- } \\
\text { de com as normas } \\
\text { de segurança. }\end{array}$ & 2 & $\begin{array}{l}80 \\
M\end{array}$ \\
\hline
\end{tabular}




\begin{tabular}{|c|c|c|c|c|c|c|c|c|}
\hline $\begin{array}{c}\text { Atividades } \\
\text { desenvolvidas }\end{array}$ & $\begin{array}{l}\text { Aspectos } \\
\text { ambientais }\end{array}$ & Impactos & G & Causa Potencial & 0 & $\begin{array}{l}\text { Forma atual } \\
\text { de controle }\end{array}$ & D & IRA \\
\hline \multirow[t]{4}{*}{$\begin{array}{l}\text { Preparação/ } \\
\text { serviço de ali- } \\
\text { mentos }\end{array}$} & \multirow[t]{4}{*}{$\begin{array}{l}\text { Emissões at- } \\
\text { mosféricas. } \\
\text { Geração de re- } \\
\text { síduos. } \\
\text { Saúde do trab. } \\
\text { e clientes. }\end{array}$} & $\begin{array}{l}\text { Cont. hu- } \\
\text { mana. }\end{array}$ & 8 & $\begin{array}{l}\text { Ingestão de ali- } \\
\text { mentos } \\
\text { Contaminados. }\end{array}$ & 3 & $\begin{array}{l}\text { Limpeza do local, } \\
\text { uso de touca, botas } \\
\text { e luvas durante a } \\
\text { preparação dos ali- } \\
\text { mentos. } \\
\text { Disponibilidade de } \\
\text { pias e detergente } \\
\text { para higiene das } \\
\text { mãos. }\end{array}$ & 4 & $\begin{array}{l}96 \\
\mathbf{M}\end{array}$ \\
\hline & & \begin{tabular}{|c|} 
Cont. \\
água, solo \\
e ar. \\
\end{tabular} & 6 & $\begin{array}{l}\text { Emissões gaso- } \\
\text { sas e efluentes } \\
\text { líquidos. }\end{array}$ & 9 & $\begin{array}{l}\text { Efluentes lançados } \\
\text { em esgoto comum. }\end{array}$ & 2 & $\begin{array}{c}108 \\
M\end{array}$ \\
\hline & & Incêndio & 9 & $\begin{array}{l}\text { Vazamento de } \\
\text { gás, curto-cir- } \\
\text { cuito e uso de } \\
\text { produtos infla- } \\
\text { máveis. }\end{array}$ & 4 & $\begin{array}{l}\text { Qualidade das ins- } \\
\text { talações elétricas, } \\
\text { placas de sinaliza- } \\
\text { ção. }\end{array}$ & 2 & $\begin{array}{l}72 \\
M\end{array}$ \\
\hline & & Resíduos. & 5 & $\begin{array}{l}\text { Descarte inade- } \\
\text { quado. }\end{array}$ & 5 & $\begin{array}{l}\text { Venda do óleo de } \\
\text { cozinha para reci- } \\
\text { cladora. } \\
\text { Coleta da prefeitu- } \\
\text { ra. }\end{array}$ & 1 & $\begin{array}{l}25 \\
\text { B }\end{array}$ \\
\hline $\begin{array}{l}\text { Comerc. de pro- } \\
\text { dutos }\end{array}$ & $\begin{array}{l}\text { Geração de re- } \\
\text { síduos. }\end{array}$ & Resíduos. & 4 & $\begin{array}{l}\text { Descarte inade- } \\
\text { quado. }\end{array}$ & 6 & $\begin{array}{l}\text { Coleta da prefeitu- } \\
\text { ra. }\end{array}$ & 1 & $\begin{array}{c}24 \\
B\end{array}$ \\
\hline $\begin{array}{l}\text { Atividades adm. } \\
\text { e manutenção } \\
\text { do serviço. }\end{array}$ & $\begin{array}{l}\text { Geração de re- } \\
\text { síduos. }\end{array}$ & Resíduos. & 4 & $\begin{array}{l}\text { Descarte inade- } \\
\text { quado. }\end{array}$ & 3 & $\begin{array}{l}\text { Coleta da prefeitu- } \\
\text { ra. }\end{array}$ & 1 & $\begin{array}{c}12 \\
\mathbf{B}\end{array}$ \\
\hline \multirow[t]{3}{*}{$\begin{array}{l}\text { Lavagem } / \mathrm{ma-} \\
\text { nutenção dos } \\
\text { banheiros }\end{array}$} & \multirow{3}{*}{$\begin{array}{l}\text { Geração de re- } \\
\text { síduos. } \\
\text { Saúde do tra- } \\
\text { balhador. } \\
\text { Emissões de } \\
\text { efluentes líqui- } \\
\text { dos. }\end{array}$} & $\begin{array}{l}\text { Cont. hu- } \\
\text { mana. }\end{array}$ & 8 & $\begin{array}{l}\text { Contato com } \\
\text { bactérias e pro- } \\
\text { dutos de limpe- } \\
\text { za. }\end{array}$ & 9 & $\begin{array}{l}\text { Uso de EPI's } \\
\text { (exceto avental). }\end{array}$ & 4 & $\begin{array}{c}288 \\
\text { A }\end{array}$ \\
\hline & & $\begin{array}{c}\text { Cont. água } \\
\text { e solo. }\end{array}$ & 5 & $\begin{array}{l}\text { Efluentes líqui- } \\
\text { dos. }\end{array}$ & 4 & Esgoto comum. & 2 & $\begin{array}{l}40 \\
\mathbf{B}\end{array}$ \\
\hline & & Resíduos. & 5 & $\begin{array}{l}\text { Descarte inade- } \\
\text { quado. }\end{array}$ & 5 & $\begin{array}{l}\text { Coleta da prefeitu- } \\
\text { ra. }\end{array}$ & 1 & $\begin{array}{c}25 \\
\text { B }\end{array}$ \\
\hline
\end{tabular}

Quadro 5 - Formulário do FMEA, aplicado no Posto Alfa.

Fonte: elaboração a partir de dados da pesquisa (2011).

De acordo com as informações explicitadas no Quadro 5, o Posto Alfa apresenta como impacto de alto risco ambiental o de contaminação humana, exceto nas atividades de recebimento/armazenagem e preparação/serviço de alimentos, as quais apresentam um índice de contaminação humana de médio risco. As atividades que obtiveram o IRA considerado alto em relação à contaminação humana foram a de abastecimento e lavagem/manutenção dos banheiros, com índices, respectivamente, de 252 e 288. Pode-se justificar o valor elevado desse índice nas respectivas atividades devido a não efetiva utilização dos EPI's disponibilizados pela empresa. Questionado sobre tal prática de não uso desses equipamentos pelos seus funcionários, o proprietário afirmou que tenta convencê-los da importância do uso dos EPI's, mas que nunca utilizou advertência formal ou suspensão por conta de tal irregularidade.

Contudo, merece destaque o descaso com o uso dos EPI's, visto que estas atividades que apresentaram expressividade no IRA propiciam risco de contaminação devido aos funcionários serem expostos a emissões gasosas e a componentes químicos que agridem a pele e os olhos, principalmente no que tange aos combustíveis no ato do abastecimento, causando-lhes 
sérios danos à saúde, como destacado no Quadro 1 por Loureiro et al. (2002) e Marques et al. (2003). A fim de reduzir o IRA nesse contexto, aconselha-se a empresa a investir em treinamento de sensibilização por pessoas especializadas na área antes de adotar o sistema formal de punição previsto em lei para quem não cumpre com a obrigatoriedade da utilização de EPI's.

Em contrapartida, os impactos de médio risco que se destacaram no formulário aplicado foram os de contaminação do solo, da água e do ar e o de incêndio. No que tange à contaminação do solo, da água e do ar, o IRA teve expressividade na atividade de preparação e serviços dos alimentos, atingindo o valor de 108, já que existe grande lançamento de emissões gasosas e efluentes líquidos sem formas atuais de controle para mitigar tais lançamentos. As emissões gasosas oriundas da queima de lenha do forno utilizado para preparar os alimentos deterioram a qualidade do ar; já os efluentes líquidos lançados em esgoto comum sem tratamento podem gerar contaminação do solo e de águas subterrâneas.

Quanto ao médio risco ambiental relacionado a incêndio, verifica-se que, na atividade de recebimento e armazenamento, bem como abastecimento, tem-se um IRA igual a 80. Já no que tange a esse risco quanto à atividade de preparação e serviço de alimentos, tem-se um IRA igual a 96. A expressividade do IRA referente ao impacto de incêndio deve-se ao fato de a manipulação de materiais inflamáveis e utilização de fogo na preparação de alimentos ser uma combinação perigosa. Conforme destacam Rocha et al. (2004), estes impactos estão relacionados aos efeitos causados pela ocorrência de incêndio, uma vez que as possíveis consequências de um incêndio podem acarretar danos aos funcionários, aos clientes, aos proprietários e à vizinhança, podendo ocasionar vítimas fatais. É justificada a média gravidade do risco de incêndio devido às formas atuais de controle serem eficientes; contudo, o risco de acidente não é nulo, e, caso este ocorra, os impactos são graves.

Quanto às atividades que apresentam um baixo risco ambiental referente aos seus impactos, identificou-se que, em recebimento e armazenamento, tem-se um IRA igual a 50 para o impacto de contaminação da água e do solo. Nas atividades de abastecimento e lavagem/manutenção e banheiros, este mesmo impacto apresentou IRA igual a 30 e 40, respectivamente. Isso indica que os mecanismos de controle desse impacto nas atividades identificadas permitem uma segurança quanto à baixa probabilidade de sua ocorrência.

Vale ressaltar que, quanto aos resíduos, verificou-se um IRA variando de 12 a 30 (ver Quadro 5), o que demonstra baixo risco ambiental. Isso pode ser justificado pela efetiva ação da empresa no gerenciamento dos resíduos, a exemplo do óleo de cozinha, que é destinado a uma recicladora, e das flanelas usadas no abastecimento, que são recolhidas por uma empresa especializada. No entanto, deve-se destacar que, mesmo apresentando um baixo IRA, este pode ser reduzido se a empresa tomar outras medidas de destinação de resíduos além da simples coleta da prefeitura. Neste caso, a reciclagem apresenta-se como alternativa.

Por último, pode-se verificar que os impactos analisados não apresentaram índices muito baixos ou muito altos quanto ao risco. Após apresentados e analisados os dados coletados, a seguir, serão explicitadas as conclusões acerca deste estudo.

\section{CONCLUSÕES}

Diante do objetivo proposto, o presente trabalho buscou a priori descrever as atividades desenvolvidas no Posto Alfa, a fim de verificar os seus procedimentos operacionais e o impacto ambiental por estes gerados. Foram identificados, com base na classificação dada por Rocha et al. (2004), os potenciais impactos de contaminação humana; contaminação do solo e da água subterrânea; incên- 
dios; e resíduos causados pelas atividades do posto Alfa. Nesse sentido, verificou-se que potenciais impactos identificados neste estudo ratificam os impactos expostos por Rocha et al. em seu trabalho.

Para tanto, a fim de prevenir tais impactos, recomendam-se algumas iniciativas além das já praticadas pela empresa. No que tange aos impactos de contaminação humana, verificase a necessidade de um rigor no uso dos Equipamentos de Proteção Individual (EPI's), ou seja, a obrigatoriedade do uso de luvas e máscaras durante o abastecimento, do uso de aventais impermeáveis na limpeza dos banheiros, do fardamento completo para os ajudantes do restaurante e da disposição de pratos e copos em compartimentos fechados.

No que se refere aos impactos de contaminação de solo e da água subterrânea, pode-se verificar que as iniciativas de instalações dos tanques da empresa tendem a manter sobre controle esse risco. Contudo, sugere-se treinamento dos funcionários no que concerne ao abastecimento de veículos, visando evitar derramamentos superficiais.

Para os impactos referentes a incêndio, recomenda-se que a empresa disponibilize um treinamento para seus funcionários acerca da prevenção deste tipo de acidente, incluindo os procedimentos a serem tomados no caso de ocorrência do mesmo. Dessa forma, os incêndios podem ter o seu risco de ocorrência minimizado ou a gravidade de seus possíveis impactos diminuída se os procedimentos corretos forem adotados.

No caso dos resíduos identificados (flanelas contaminadas com resíduos tóxicos, efluentes líquidos, óleo de cozinha, dentre outros), observou-se que a empresa procura destinar corretamente os resíduos mais perigosos. No entanto, falta providenciar uma destinação adequada aos materiais que podem ser reciclados.

Uma vez identificados os potenciais impactos, a aplicação do FMEA propiciou a distinção, por meio do Índice de Impacto Ambiental (IRA), das atividades que geram maior risco de impacto, a exemplo do abastecimento e da lavagem/manutenção dos banheiros, bem como da preparação/serviço dos alimentos, quanto a maior risco de contaminação humana. É importante ressaltar que o presente estudo contribui para a disseminação da avaliação de impacto ambiental nas empresas do setor e serve como base para que estas possam conhecer os impactos gerados por suas atividades. Outra contribuição é que a utilização do método FMEA promove a possibilidade de constante avaliação do risco ambiental e a adoção de ações para mitigá-lo, o que conduzirá a organização à melhoria de seus processos e ao acompanhamento de melhoria por meio da mensuração dos índices de criticidade.

Por fim, ressalva-se que o presente estudo apresenta como limitações o fato de o método FMEA ser de caráter dedutivo, podendo, assim, levar a uma variação dos resultados de acordo com o ponto de vista do pesquisador, além de se restringir às conclusões deste. Além disso, tratase de um estudo de caso único, não devendo representar o comércio varejista de combustíveis da região como um todo. Nesse sentido, sugere-se que trabalhos futuros sejam realizados neste contexto, com equipes multidisciplinares (visão ampla), a fim de mapear os impactos ambientais gerados pelos postos de combustíveis da região. 


\section{REFERÊNCIAS}

ANDRADE, M.R.S; TURRIONI, J.B. Uma metodologia de análise dos aspectos e impactos ambientais através do FMEA. XX Encontro Nacional de Engenharia de Produção - ENEGEP, 2000, USP/ POLI-SP.

BARASUOL, Bueno Robson et. al. FMEA Uma Abordagem Simplificada. XXI Congresso de Iniciação Científica e Tecnológica em Engenharia-CRICTE, 2006, Petrópolis.

CONAMA, Conselho Nacional do Meio Ambiente. Disponível em:< http://www.mma. gov.br/conama〉>. Acesso em 12 fev.2011.

COIMBRA, Marceli de Menezes. Aplicação da análise de modo e efeitos de falha potencial (FMEA) para avaliação de significância de aspectos e impactos ambientais da indústria cerâmica. 2003. Dissertação (mestrado) Universidade Estadual de Campinas, Instituto de Geociências, Campinas-SP.

DONAIRE, Denis. Gestão Ambiental na Empresa. 2. Ed. São Paulo: Atlas, 2007.

EISENHARDT, K. M. Building Theories from Case Study Research. Academy of Management Review, v. 14, n. 4, p. 532-550, 1989.

GIL, Antônio Carlos. Como elaborar Projetos de Pesquisa. 3. Ed. São Paulo: Atlas, 1996.

JUNIOR, et all. Levantamentos de aspectos e impactos ambientais do Instituto Federal de Educação , Ciência e Tecnologia de Mato Grosso, campos de Cuiabá - Bela Vista. II Congresso Brasileiro de Gestão Ambiental, 2011, Londrina-PR.

KUMRU, Mesut; KUMRU, Pınar Yıldız. Fuzzy FMEA application to improve purchasing process in a public hospital. Applied Soft Computin V. 13,pg 721-733, 2012.

LORENZETT, D.B; ROSSATO, M.V. A Gestão de Resíduos em Postos de Abastecimento de Combustível. XIII Seminários em Administração
- SEMEAD, 2010, FEA/USP-SP.

LOUREIRO, C. de O.; OLIVEIRA, L.I. De; RODRIGUES O. De O. A.; COSTA, W.D. Postos Distribuidores de combustíveis e o problema ambiental em Belo Horizonte. XII Congresso Brasileiro de Águas Subterrâneas, Florianópolis, 2002. Santa Catarina.

MARCONI, Marina de Andrade; LAKATOS, Eva Maria. Técnicas de Pesquisa: planejamento e execução de pesquisas, amostragens e técnicas de pesquisa, elaboração, análise e interpretação de dados. São Paulo: Atlas, 1999.

MARQUES, C.E.B; PUGAS, C.G.S.; SILVA, F.F. da; MACEDO, M.H.A. de, O licenciamento ambiental dos postos de revenda varejista de combustíveis de Goiânia. 2003. Disponível em:< http://www.ucg.br/nupenge/pdf/ art0005.pdf>. Acessado em 20 nov.2010.

MARTINS, Manoel Fernando; ZAMBRANO, Tatiane Fernandes. Utilização da metodologia FMEA para análise dos impactos ambientais em uma empresa do ramo de usinagem. XXIII Encontro Nacional de Engenharia de Produção - ENEGEP, 2003, Ouro Preto-MG.

OLIVEIRA, L. N. ; FREITAS, L. S. O uso do FMEA como ferramenta de avaliação dos aspectos e impactos ambientais numa indústria de microeletrônica. XIII ENGEMA Encontro Nacional sobre Gestão Empresarial e Meio Ambiente, 2011, São Paulo.

PORTUGAL JR, Pedro dos Santos; PORTUGAL, Nilton dos Santos. Microeconomia e meio ambiente: Análise de fundamentos microeconômicos inerentes à gestão ambiental nas organizações. Revista de Adm. UFSM, Santa Maria, v. 3, n. 3, p. 393-410, 2010.

ROCHA, Sandra P.B; et al. Análise dos Impactos Ambientais causados pelos Postos de distribuição de Combustíveis: uma visão integrada. Anais XXIV Encontro Nacional de Engenharia de Produção - ENEGEP, 2004, Santa Catarina. 
SILVA, Ricardo dos Santos de. Avaliação de impactos e custos ambientais em processos industriais- Uma abordagem metodológica. 2003. Dissertação (mestrado) em Engenharia de Produção, Federal do Rio Grande do Sul, , Porto Alegre-RS.

SPERANDIO, Sérgio Antônio; GASPAR, Marcos Antônio. Gestão Socioambiental em Empresas Industriais. Revista de Adm. UFSM, Santa Maria, v. 2, n. 1, p. 21-40, 2009.

VANDENBRANDE, W. W. How to use FMEA to reduce the size of your quality toolbox; Quality Progress. v.31, n.11, 1998, p. 97-100.

VELTER, Aline Nadalin; et al. Atitudes dos consumidores a partir da teoria das pistas e da consciência ambiental: contribuições do estudo do green marketing. Revista de Adm. UFSM, Santa Maria, v. 2, n. 3, p. 399-416, 2009.

WENCESLAU, Franclin Ferreira; ROCHA, Jefferson Marçal da. A ferramenta de análise FMEA como suporte para identificação dos aspectos e impactos ambientais em uma agroindústria de arroz. TECNO- LÓGICA v. 16, n.1, p. 56-66 jan./jun. 2012.

YIN, R. K. Estudo de Caso: planejamento e métodos. Tradução de Daniel Grassi. 3a ed. Porto Alegre: Bookman, 2005. 